\title{
CASO CLÍNICO: MANEJO NUTRICIONAL EM PACIENTE PEDIÁTRICO COM PSEUDO- OBSTRUÇÃO INTESTINAL
}

\section{Pôster}

Autores deste trabalho:

Rafaela Rodrigues Vieira: Instituto da Criança - HCFMUSP

Maria Aparecida Carlos Bonfim: Instituto da Criança - HCFMUSP

Adriana Servilha Gandolfo: Instituto da Criança - HCFMUSP

Área do Trabalho: Nutrição

Data da submissão:31/07/2018 às 12:42

\section{Justificativa}

Não se aplica (caso clínico)

\section{Objetivo(s)}

Não se aplica (caso clínico)

\section{Método(s)}

Não se aplica (caso clínico)

\section{Resultado(s)}

Introdução: A pseudo-obstrução intestinal é caracterizada pela presença de sinais e sintomas de oclusão intestinal, na ausência de obstrução mecânica. Paciente MCLV, gênero feminino, procedente de Belém. Diagnóstico prévio de megacólon congênito aos 12 meses de vida, após iniciar quadro de constipação crônica aos 7 meses de vida. Foi realizado abaixamento de cólon, evoluindo com bridas e submetida à reabordagens cirúrgicas e confecção de ileostomia. Admitida em serviço de pronto atendimento (PA), devido quadro de hipoatividade, baixa aceitação alimentar, distensão e dor abdominal, redução do débito da ileostomia e da diurese. Informações clínicas: Após 3 dias no PA, transferida para a enfermaria de cirurgia infantil. Sendo realizados exames adicionais, além de biópsia de retal e da ileostomia. Posteriormente, as lâminas das biópsias realizadas no serviço de origem foram revisadas, definindo-se o diagnóstico de pseudo- obstrução intestinal. Conduta terapêutica: Prescrito jejum e reposição hipovolêmica.

Após estabilidade hemodinâmica iniciou-se a administração de nutrição parenteral padrão, que oportunamente foi alterada para uma formulação individualizada, com oferta calórica de $580 \mathrm{kcal} /$ dia e proteica de $15 \mathrm{~g} / \mathrm{dia}$. Após compensação do quadro clinico foi iniciada dieta líquida sem leite e sem sacarose por via oral. Acompanhamento clínico: Paciente com alto risco nutricional (StrongKids). Ocorreu ganho ponderal de $2,0 \mathrm{~kg}$ e sem alteração estatural. $O$ índice Peso/Comprimento evoluiu do escore-z $-2,76$ para $-1,45$. A circunferência do braço também apresentou melhora, de $11 \mathrm{~cm}$ na avaliação inicial, para $12,5 \mathrm{~cm}$ na última avaliação realizada. Foram realizados dois exames de bioimpedância elétrica, com alteração do ângulo de fase inicial de 3,4 para 5,4 . A média das necessidades foi de $605 \mathrm{Kcal} /$ dia e de 23g/dia de proteínas. 


\section{Conclusão (ões)}

A terapia nutricional individualizada repercutiu positivamente na estabilização do quadro clinico e melhora do estado nutricional e geral da paciente. 